\title{
Deafness-genital anomalies-metacarpal and metatarsal synostosis syndrome
}

INSERM

\section{Source}

INSERM. (1999). Orphanet: an online rare disease and orphan drug data base. Deafnessgenital anomalies-metacarpal and metatarsal synostosis syndrome. ORPHA:3224

Deafness-genital anomalies-metacarpal and metatarsal synostosis syndrome is characterised by sensorineural deafness, bilateral synostosis of the 4th and 5th metacarpals and metatarsals, genital anomalies (hypospadias in males), psychomotor delay and abnormal dermatoglyphics. So far, it has been described in two unrelated patients. Facial dysmorphism was noted in both patients (prominent forehead, ear anomalies, facial asymmetry and an open mouth appearance). 